\title{
Temporal pattern of feeding and drinking behaviour of gestating sows
}

\author{
Stephan Kruse', Eckhard Stamer' ${ }^{2}$, Imke Traulsen ${ }^{1}$ and Joachim Krieter ${ }^{1}$ \\ 'Institute of Animal Breeding and Husbandry, Faculty of Agricultural and Nutritional Sciences, Christian-Albrechts- \\ Universität zu Kiel, Kiel, Germany, ${ }^{2} \mathrm{TiDa}$ Tier und Daten GmbH, Westensee/Brux, Germany
}

\begin{abstract}
The aim of the present study was to investigate the temporal pattern of feed and water intake behaviour of gestating sows housed in a dynamic group. The dataset included 90 sows (parity 1 to 7). Feed and water intake were recorded by electronic feeding and drinking stations. To describe the feed and water intake behaviour single visits were combined into meals and drinking bouts. A log survivorship function identified the characteristic interval length to differentiate between two bouts. Interval lengths larger than 12 min separated two meals ( 29 min two drinking bouts). The meal and drinking bout criteria were used to derive the following traits: feeding and drinking duration per day (FD, DD), interval duration within feeding (pauseF) or drinking (pauseW) meal, feeding and drinking meal duration per day (FMD, DMD) and feeding and drinking visits per day (FV, DV). Additionally, an eating rank was calculated according to the order of the sows at the feeding station. The results showed that nulliparous and primiparous sows had higher FD, pauseF, FMD and FV in contrast to biparous and multiparous sows $(P<0.05)$. The DD of primiparous sows was significantly lower than that of older sows. The eating rank increased over time while nulliparous sows increased their rank more slowly than older sows. Low to moderate repeatabilities were found for feed intake traits ( 0.23 to 0.41$)$; higher repeatabilities for drinking traits $(0.45$ to 0.55$)$ and eating rank ( 0.71$)$ indicating high variation between sows, which could be used for the identification of diseases.
\end{abstract}

Keywords: sow, gestation, water intake behaviour, meal criterion

\section{Zusammenfassung}

\section{Zeitliche Muster im Futter und Wasseraufnahmeverhalten von tragenden Sauen}

Ziel der vorliegenden Studie war die Untersuchung von zeitlichen Mustern im Futter- und Wasseraufnahmeverhalten tragender Sauen. Eine dynamische Gruppe mit 90 Sauen (Parität 1 bis 7) stand als Datenmaterial zur Verfügung. Elektronische Futter- und Wasserabrufstationen ermöglichten die Erfassung einzelner Besuche. Die Anwendung einer Überlebenskurve diente zur Einteilung von Mahlzeiten aus den einzelnen Besuchen. Bei Intervallen länger als 12 (Futter) bzw. 29 (Wasser) Minuten wurde von zwei Mahlzeiten ausgegangen. Auf Basis des Mahlzeitenkriteriums wurden folgende Merkmale abgeleitet: Dauer der Futterund Wasseraufnahme (FD, DD), Unterbrechungsdauer zwischen zwei Futter (pauseF) bzw. Wasseraufnahmeabschnitten (pauseW) in einer Mahlzeit, Dauer der Futter- und 
Wasseraufnahme je Tag (FMD, DMD) sowie Anzahl der Futter- und Wasseraufnahmebesuche (FV, DV). Zusätzlich wurde ein Fressrang abgeleitet, der die Reihenfolge der Sauen an der Futterstation beschreibt. Die Ergebnisse zeigen, dass nulli- und primipare Sauen höhere FD, pauseF, FMD und FV aufweisen als bi- und multipare Sauen $(P<0,05)$. Die DD der primiparen Sauen war signifikant geringer als die der älteren Sauen $(P<0,05)$. Mit zunehmender Aufenthaltsdauer in der dynamischen Sauengruppe stieg der Fressrang an. Dabei erhöhte sich der Fressrang von nulliparen Sauen langsamer als derjenige der älteren Sauen. Geringe bis mittlere Wiederholbarkeiten wurden für die Merkmale des Futteraufnahmeverhaltens festgestellt $(0,23$ bis 0,41$)$. Dahingegen konnten höhere Werte für die Merkmale des Wasseraufnahmeverhaltens $(0,45$ bis 0,55$)$ sowie des Fressranges $(0,71)$ ermittelt werden, die eine hohe Variation zwischen den Sauen deutlich machen. Diese Variation kann zur Identifikation von Erkrankungen herangezogen werden.

Schlüsselwörter: Sau, Trächtigkeit, Wasseraufnahmeverhalten, Mahlzeitenkriterium

\section{Introduction}

Feed intake behaviour of growing pig was the objective of several studies (Ingram \& Dauncey 1985, Bigelow \& Houpt 1988, De Haer \& Merks 1992, Musial et al. 1999, Morgan et al. 2000). For sows only few information can be found (Bressers et al. 1993, Brouns \& Edwards 1994, Arey 1999, Beyga \& Rekiel 2010). The studies of Bigelow \& Houpt (1988) as well as Musial et al. (1999) observed that feed intake of pigs fed ad libitum was higher during the day than during the night. The pattern during the day was not analysed further. Brouns \& Edwards (1994) investigated the feed intake behaviour of sows fed ad libitum. The authors observed that sows spent $91 \mathrm{~min} /$ day on feeding but gave neither information on when the feed intake nor how many feed intake observations (meals) occurred during the day.

Nowadays, group housing is a commonly used system to house gestating sows. The EU Commission has regulated that from 2013 onwards all gestating sows have to be housed in groups. Therefore, electronic feeding stations have been widely implemented into such systems and become more and more important. In consequence, for each sow and visit to the feeding station information on the identification of the animal, the amount of feed intake and the times of starting and ending the feed consumption event are recorded automatically. This kind of data has been used to describe the feeding behaviour of cows (Stamer et al. 1997) and growing pigs (De Haer \& Merks 1992, Morgan et al. 2000). To our knowledge, water and restricted feed intake behaviour of loose-housed sows fed by electronic feeding stations has not yet been described in literature. The aim of the present study was to investigate the feed and water intake behaviour of gestating sows housed in a dynamic group. Focus was put on the temporal pattern during the day and variations during lactation.

\section{Materials and methods}

\section{Animals and housing}

Data were recorded at the Hohenschulen research farm of the Institute of Animal Breeding and Husbandry of the University of Kiel between April 2007 and June 2008. The observed sow 
herd had a size of 90 sows (Large White, German Landrace and their crossbreeds) in parities 1 to 7 (144 pregnancies). In the gestating unit, sows were kept in a dynamic group with an average size of 26 sows. The sows were moved into the gestating unit after pregnancy diagnosis. The compartment $(7.20 \times 9.10 \mathrm{~m})$ had a running area with a slatted floor, two electronic sow feeders (open feeding stations), two nipple drinkers and six resting areas (three subunits per side) with a concrete floor (Figure 1). The compartment temperature was monitored by a climate computer to maintain a room temperature between $18^{\circ} \mathrm{C}$ and $20^{\circ} \mathrm{C}$. The light program started every morning at 06:00 a.m. and ended in the evening at 10:00 p.m.

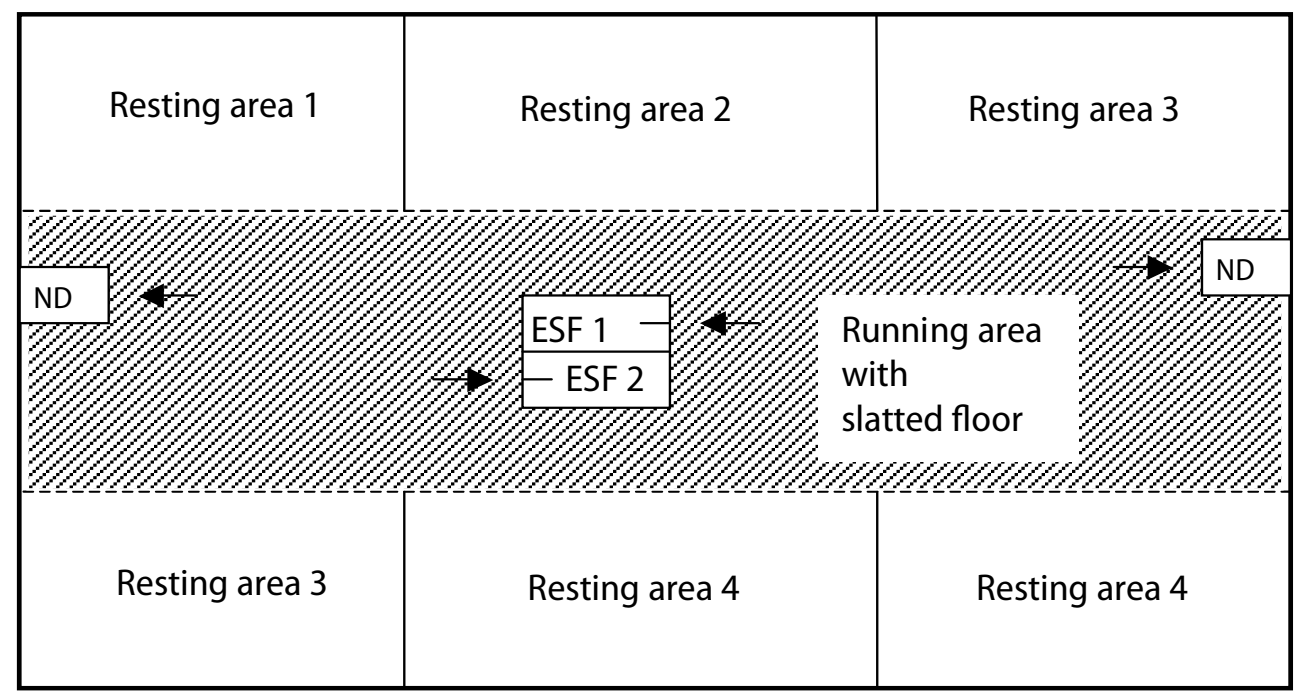

Figure 1

Gestating unit with six resting areas, two electronic sow feeders (ESF 1 and 2) and two water stations with nipple drinkers (ND); arrows indicate the access direction

\section{Water and feed recording}

Water and feed intake per visit at the water and feeding stations were recorded automatically for each identified sow.

Each sow had an individual demand of feed that was adapted to its parity and individual body condition. Sows were able to consume the feed in a single meal or to divide it into several meals. The feeding period started every morning at 06:00 a.m. and ended at 10:00 p.m. (end of the lighting phase). Visits between 10:00 p.m. and 06:00 a.m. ( $<3 \%$ of all visits) were excluded from the dataset Identification of the sow, beginning and end of feed intake as well as amount of feed intake were recorded at the feeding station. The sows received a commercial gestating diet $(15.2 \%$ crude protein, $5.2 \%$ crude fat, $7.2 \%$ crude fibre, $12.4 \mathrm{MJME} / \mathrm{kg}$ dry matter) according to the German norm (GfE 2006).

The sows had free access to water during the whole day. The individual water intake of each visit was measured by a water flowmeter. A sensor in the water flowmeter produced a flow proportional frequency and was stored. The water flowmeter provided an accuracy of $2 \%$ of full scale, i.e. the variation was $2 \%$ of the daily water intake of each sow. Information for each drinking events were recorded analogous to the feed intake. 


\section{Definition of feeding and drinking bouts}

The bouts for feed and water intake behaviour were derived from the single visits of the gestating sows to the feeding and water stations (Musial et al. 1999).

To separate the visits over time into bouts, it was necessary to identify a characteristic interval length between visits that clearly distinguished visits within bouts from those between bouts (=meal criterion). For an objective definition of the meal criterion, a log survivorship curve of the intervals was used (Slater \& Lester 1982, Sibly et al. 1990). This curve results from a cumulative frequency of the gaps between visits greater than a particular length (on a logarithmic scale) plotted against gap length (on a linear scale). Such plots are often characterised by a concave trajectory, descending steeply at first (high probability of a further visit; intervals classified as within-bout), and subsequently much more gradually (low probability of a further visit; intervals classified as between bouts) (Slater \& Lester 1982). The point where the slope changes most essentially, usually represents the interval length for bout definition.

The breakpoints (meal criterion) of the feed and water curves were determined by the formula according to Slater \& Lester (1982).

$$
T_{f, w}=\frac{1}{b_{1}-\left(b_{1}+b_{2}\right)} \log _{e} \frac{N_{w}}{N_{b}}
$$

where $T_{f, w}$ is the meal criterion for feed (f) and water (w) intake, $b_{1}$ is the probability of a further visit within meal, $b_{1}+b_{2}$ is the probability of a further visit between meals, $N_{w}$ is the number of intervals within meal $\left(\exp \left(b_{0}\right)\right)$ and $N_{b}$ is the number of intervals between meals.

The parameters of the two underlying negative exponential distributions were estimated by a spline approximation using the NLIN-procedure of SAS (2005) (Figure 2).

$$
y_{i}=b_{0}+b_{1} t_{i}+b_{2}\left(\max \left(t_{i}-T, 0\right)\right)
$$

where $y_{i}$ is the $i$-th loge relative cumulated frequency of interval length between visits $>t_{\text {, }}$ $b_{0}$ is the constant, $b_{1} t_{i}$ is the partial linear regression on interval length $t_{i}$ within meals and $b_{2}\left(\max \left(t_{i}-T, 0\right)\right)$ is the change in $b_{1}$ for interval length $t_{i}$ between meals.
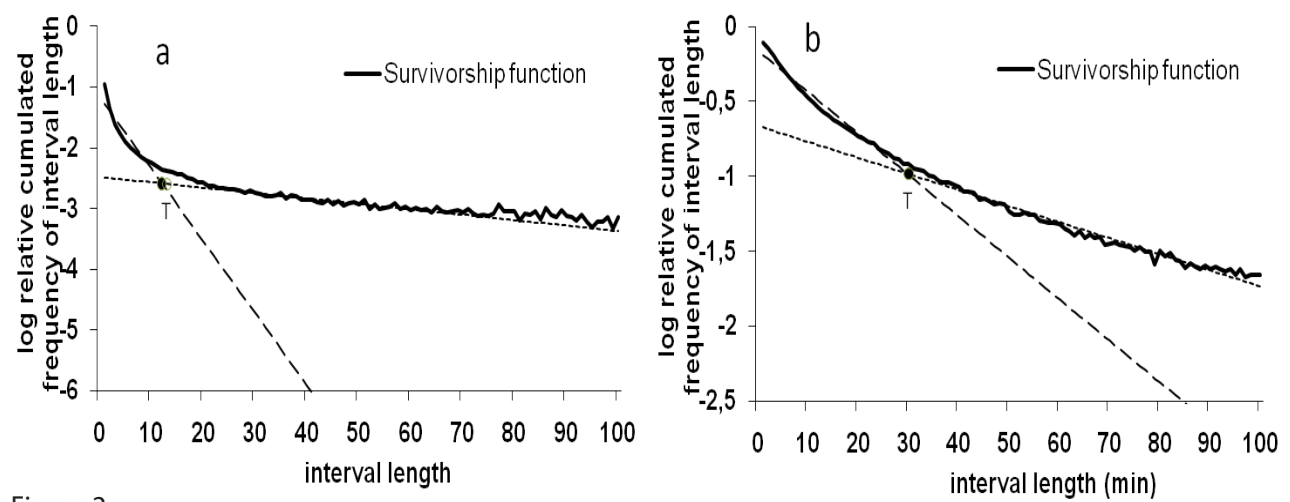

Figure 2

Log survivorship function for intervals between feed (a) and water (b) intake visits with the breakpoints (T) 
The meal criterion was calculated for feed and water intake separately. The calculated maximum interval length was 12 min between two feed intake visits within a meal $\left(T_{f}\right)$ and 29 min between two water intake visits within a meal $\left(T_{w}\right)$. Interval lengths between visits that were greater than 12 (29) min were considered to separate two meals (drinking bouts).

\section{Traits of feed and water intake behaviour}

Meals and drinking bouts were used to define five traits describing the feed and water intake behaviour: (1) number of feeding and drinking visits per sow and day (FV and DV), (2) total feeding and drinking duration per sow and day (FD and DD), (3) number of meals per sow and day, (4) total feeding and drinking meal duration per sow and day (FMD and DMD) and (5) total interval duration of feeding and drinking within meal per sow and day (pauseF and pauseW). FMD and PauseF (DMD and PauseW) sum up to FD (DD), respectively. An overview of the traits of feed and water intake behaviour is given in Table 1. Extreme values that deviated more than \pm 4 s.d. from the mean of the measured data were excluded from the datasets (i.e. $66,110,109$ and 44 observations of FD, pauseF, FMD, FV and 44, 21, 27 and 18 observations of DD, pauseW, FMD as well as DV).

Table 1

Mean, standard deviation, minimum, maximum and number of observations of the traits of feed and water intake behaviour

\begin{tabular}{|c|c|c|c|c|c|}
\hline Trait & $\mathrm{n}$ & Mean & SD & Min & Max \\
\hline \multicolumn{6}{|l|}{ Feed intake behaviour } \\
\hline $\begin{array}{l}\text { feeding duration per day }(F D)\left(\operatorname{min~}^{-1}\right) \\
\text { interval duration within feeding meal }\end{array}$ & 9.429 & 21.7 & 5.4 & 1.5 & 44.4 \\
\hline (pauseF) $\left(\operatorname{min~}^{-1}\right)$ & 9.485 & 33.3 & 27.5 & 0.0 & 160.9 \\
\hline Feeding meal duration (FMD) (min $\left.\mathrm{d}^{-1}\right)$ & 9.486 & 54.0 & 28.9 & 1.5 & 190.6 \\
\hline feeding visits per day (FV) & 9.451 & 27.6 & 20.1 & 1.0 & 113.0 \\
\hline feeding meals per day & 9.474 & 1.9 & 1.1 & 1.0 & 10.0 \\
\hline eating rank (ER) & 9.473 & 0.0 & 1.5 & -3.4 & 3.4 \\
\hline feed intake $\left(\mathrm{kg} \mathrm{d}^{-1}\right)$ & 9.682 & 2.9 & 0.6 & 0.0 & 5.2 \\
\hline \multicolumn{6}{|l|}{ Drinking behaviour } \\
\hline drinking duration (DD) $\left(\operatorname{min~}^{-1}\right)$ & 9.481 & 5.3 & 3.0 & 0.1 & 18.2 \\
\hline (pauseW) (min d-1) & 9.504 & 65.6 & 52.6 & 0.0 & 273.3 \\
\hline drinking meal duration (DMD) $\left(\operatorname{min~}^{-1}\right)$ & 9.498 & 70.9 & 52.6 & 0.1 & 285.1 \\
\hline drinking visits per day (DV) & 9.507 & 12.0 & 6.0 & 1.0 & 36.0 \\
\hline drinking meals per day & 9.492 & 4.6 & 1.7 & 1.0 & 15.0 \\
\hline water intake $\left(\mathrm{I} \mathrm{d}^{-1}\right)$ & 9.464 & 16.7 & 10.1 & 0.0 & 60.0 \\
\hline
\end{tabular}

SD: standard deviation

\section{Eating rank}

The daily and individual eating rank was calculated according to Cornou et al. (2008). The order $\left(o_{t s}\right)$ of sow $s$ coming to the feeding station was determined from the beginning of the daily feeding at day $t$. Subsequently, the relative eating rank $r E R_{t s}$ was calculated: 


$$
r E R_{t s}=\frac{o_{t s}}{N_{t}+1}
$$

$N_{t}$ represented the total number of sows in the group on day $t$. To obtain a normal distribution the individual eating rank was logarithmically transformed as written.

$$
\left.E R_{t s}=\log _{e} \mid \frac{r E R_{t s}}{1-r E R_{t s}}\right) \cdot(-1)
$$

If a sow had not consumed any feed by the end of the feeding time, the individual eating rank was equal to $N_{t}\left(E R_{t s}=\log \left(N_{t}\right) \cdot(-1)\right)$. The eating rank was multiplied by -1 so that a higher value indicates a higher eating rank.

\section{Statistical analysis}

Linear mixed models were applied using SAS (2005). The model for the traits FD, FMD, pauseF, FV, ER, DD, DMD, pauseW and DV contained the fixed effects test day and parity class as well as the regression of the duration of stay in the sow group within parity class and the random effects sow and residual. Parity was divided into four classes: nulliparous, primiparous, biparous and multiparous sows. The duration of stay in the sow group (DSG) represented the time after moving the sows into the gestating unit. The following model was used:

$$
y_{i j k l}=T D_{i}+P C_{j}+\sum b_{j m} \cdot x_{i j k l m}(D S G)+s_{k}+e_{i j k l}
$$

where $y_{i j k l}$ is the observations of FD (min d-1), FMD (min d-1), pauseF (min d-1), FV, eating rank, DD (min d-1), DMD (min d-1), pauseW (min d-1) and DV, TD is the fixed effect of the $i$-th test day $(\mathrm{i}=1, . ., 435), P C_{j}$ is the fixed effect of the $j$-th parity class $(\mathrm{j}=1, . ., 4), b_{j m}$ is the polynomial second order of duration in sow group (DSG) within the $j$-th parity class, sk is the random effect of the $k$-th sow $(\mathrm{k}=1, . ., 90)$ and $e_{i j k l}$ is the residual term.

Repeated daily measurements within the gestation of sows were assumed to contain autocorrelated repeated measures (Littell et al. 1998, Littell et al. 2006, Kramer et al. 2008). In consequence, the covariance of the residual term was modelled with the spatial (exponential) structure (SP(EXP)). The correlation declined as a function of time, which was defined as $g_{\exp }(d)=e^{(-d / \theta)}$, where $\theta$ was an unknown covariance parameter and $d$ was the distance between two measurements at time $t_{1}$ and $t_{2}, d=\left|t_{1}-t_{2}\right|$. The SP(EXP) structure modelled the covariance between $t_{1}$ and $t_{2}$ as the covariance of two measurements $\left(\operatorname{Cov}\left[Y_{t_{1}}, Y_{t 2}\right]=\sigma_{e}^{2} \cdot e^{(-(d / \theta))}\right)$, where $Y_{t 1}$ and $Y_{t 2}$ were the measurements at time points $t_{1}-t_{2}$ and $\sigma_{e}{ }^{2}$ was the error variance. The SP(EXP) covariance structure was chosen because this structure is able to include missing values (Littell et al. 2006).

All effects were tested for significance by the F-test implemented in the Mixed-Procedure in SAS (2005). The significance of differences in Least Square Means was adjusted with the Bonferroni-correction.

Homogeneity of variance of the residuals was judged by visual inspection of the plots of the standardised residuals against the predicted values. Residuals were normally distributed with homogenous variance over the whole range of the predicted estimates. 


\section{Results}

Feed and water intake of the sow group during the day

Figure 3a shows the average amount of feed intake per hour of the sow group during the day. With a feeding start at 06:00 a.m., the sows consumed the highest feed amount (11.1 kg). Subsequently, the feed intake of the sow group decreased continuously. The average feed intake per meal is shown in Figure 3b. The highest value was observed at 06:00 a.m. (3.2 kg meal ${ }^{-1}$ ). The average feed intake per meal decreased rapidly during the following two hours and remained more or less constant until the end of the feeding period at 09:00 p.m.
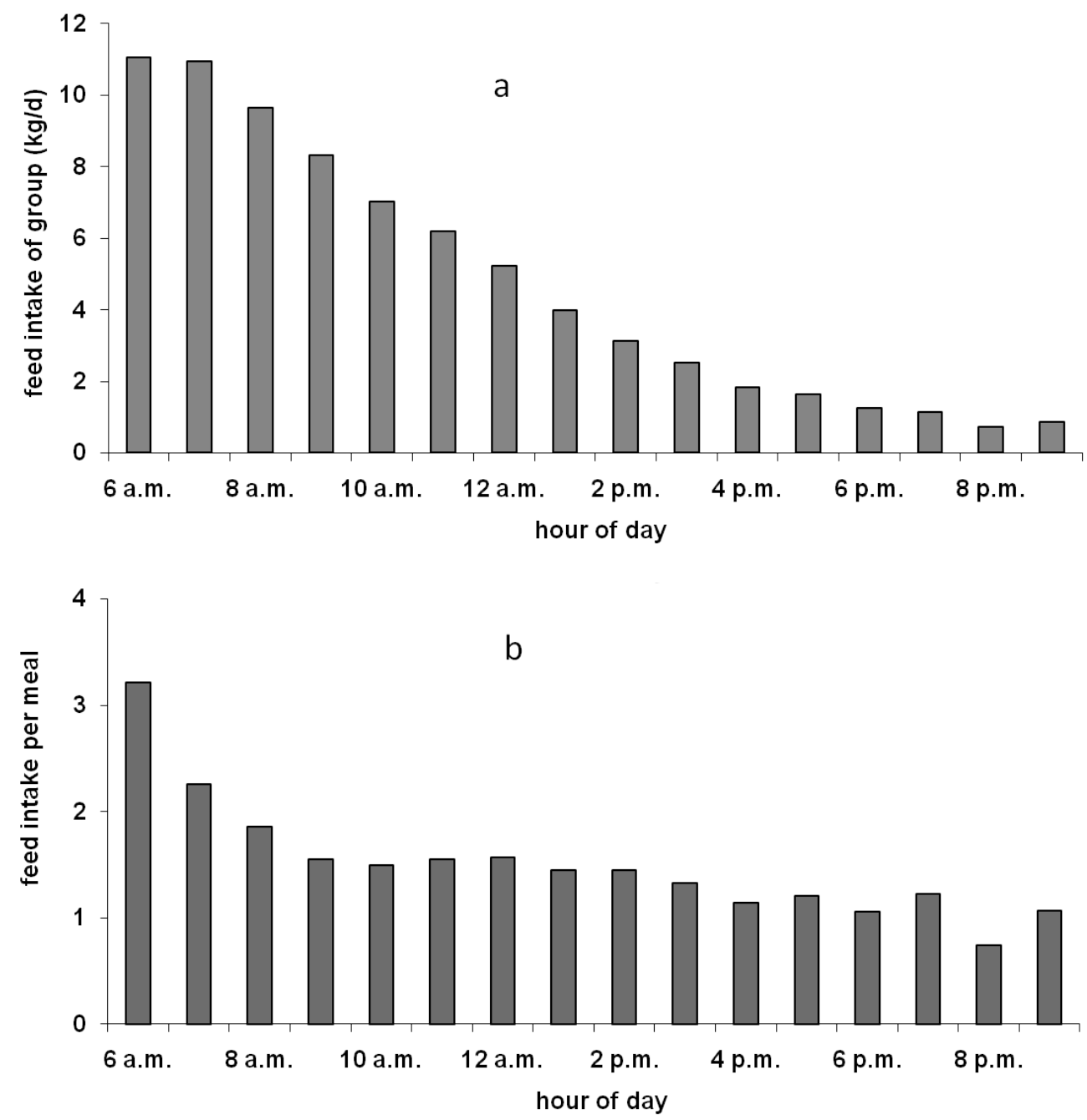

Figure 3

Total feed intake per hour (a) and feed intake per meal (b) depending on the hour of the day. 


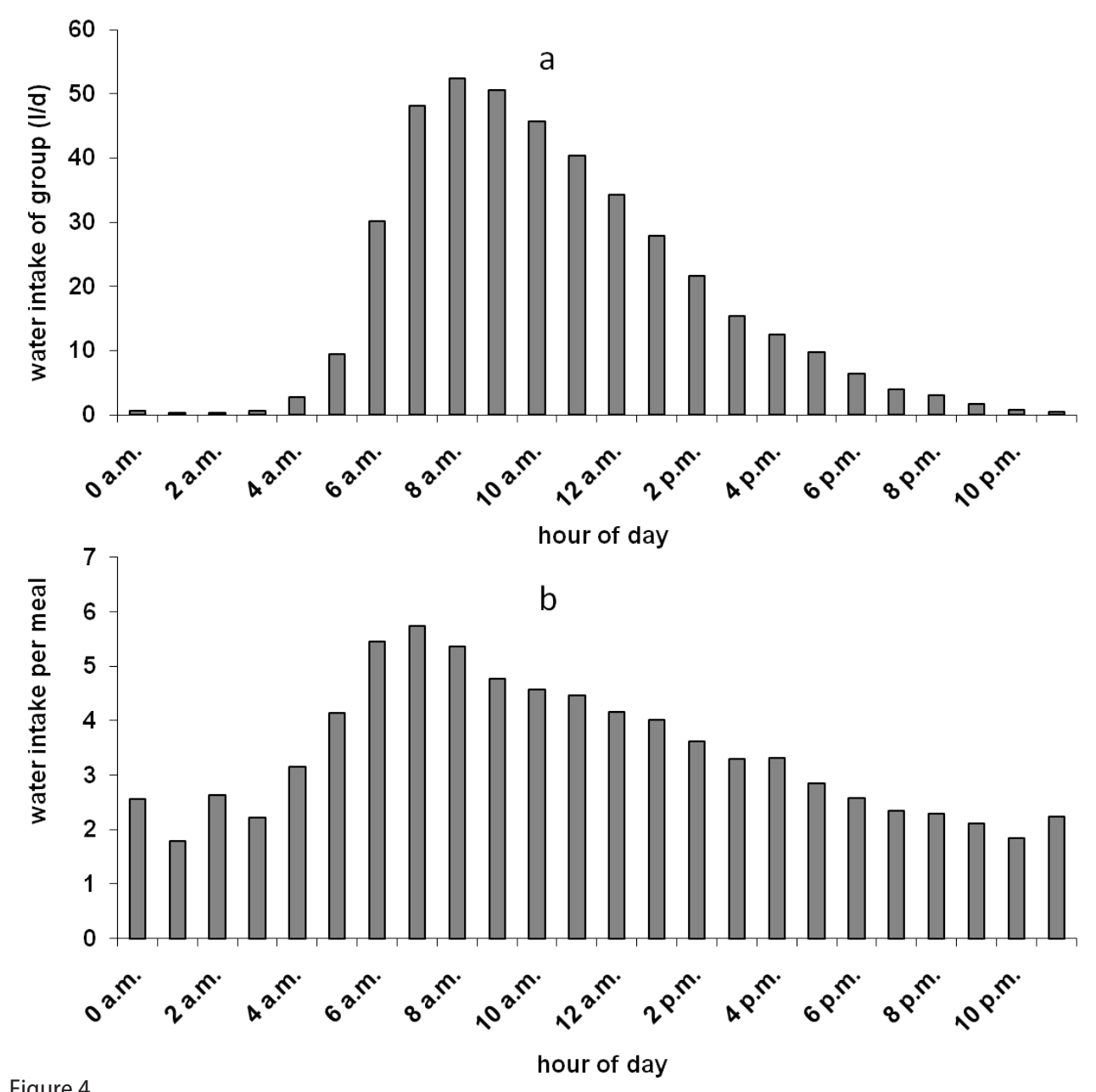

Total water intake per hour (a) and water intake per meal (b) of the sow group depending on the hour of the day

Water intake per hour of the sow group during the night was very low (Figure 4a). It increased during the morning hours, reached a maximum at 8 a.m. and decreased subsequently. Water intake per drinking bout showed an increasing course until 7 a.m. Thereafter, the intake decreased until 7 p.m. and remained relatively constant during the evening and night (Figure 4b).

\section{Analysis of the feed intake behaviour}

Parity class, test day and linear quadratic function of group membership showed a significant influence $(P<0.05)$ on the feeding duration $(F D)$, feeding meal duration per day $(F M D)$, interval duration within feeding meal (pauseF) and feeding visits per day (FV). Results for the parity class are shown in Table 2. Feeding duration was relatively constant for sows of all parities (21.5 to $22.9 \mathrm{~min}$ ). The higher the parity of a sow was, the shorter meals (FMD), shorter interruptions (pauseF) and fewer visits at the fedding station (FV) wer observed. 
Table 2

Influence of parity class on the traits of feed intake behaviour (least square means with their standard error), repeatability $(w)$ and autocorrelation $(\rho)$ for the traits of feed intake behaviour

\begin{tabular}{llccccc}
\hline \multicolumn{7}{c}{ Parity class } \\
& Nulliparous & Primiparous & Biparous & Multiparous & w & $\rho$ \\
\hline FD, min & $22.3^{\mathrm{a}, \mathrm{b}}(0.5)$ & $22.9^{\mathrm{b}}(0.4)$ & $21.8^{\mathrm{a}}(0.4)$ & $21.5^{\mathrm{a}}(0.6)$ & 0.41 & 0.64 \\
FMD, min & $62.7^{\mathrm{a}}(2.2)$ & $57.7^{\mathrm{a}}(1.6)$ & $53.4^{\mathrm{b}}(1.9)$ & $46.3^{\mathrm{c}}(2.4)$ & 0.25 & 0.43 \\
pauseF, min & $40.6^{\mathrm{a}}(2.0)$ & $34.6^{\mathrm{b}}(1.5)$ & $31.0^{\mathrm{c}}(1.7)$ & $24.1^{\mathrm{d}}(2.2)$ & 0.23 & 0.42 \\
FV & $37.3^{\mathrm{a}}(1.7)$ & $28.9^{\mathrm{b}}(1.2)$ & $25.7^{\mathrm{c}}(1.4)$ & $20.1^{\mathrm{d}}(1.8)$ & 0.28 & 0.56 \\
ER & $-1.0^{\mathrm{a}}(0.13)$ & $-0.07^{\mathrm{b}}(0.10)$ & $0.11^{\mathrm{b}}(0.11)$ & $0.45^{\mathrm{c}}(0.15)$ & 0.71 & 0.58 \\
\hline
\end{tabular}

Values with different letters are significantly different $(P<0.05)$ within row

Nulliparous sows showed a constant pattern of feeding meal duration (FMD) depending on the duration of stay in the sow group. Primiparous and biparous sows showed a decreasing course from 77 to $50 \mathrm{~min}$ (days 0 and 70) and from 66 to 45 min (days 0 and 90), respectively (Figure 5). The FMD of multiparous sows decreased rapidly until day 60 and increased during the last few days in the sow group.

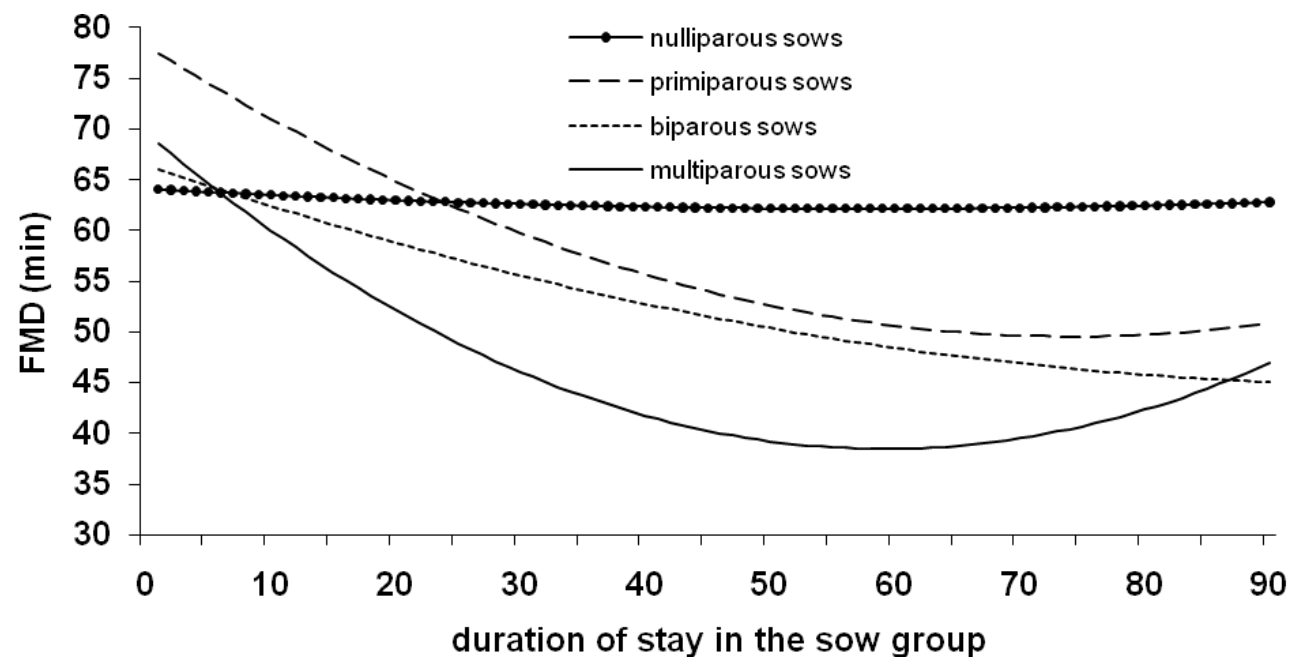

Figure 5

Daily feeding meal duration (FMD) depending on duration of stay in the sow group and parity class

Parity class, test day and duration of stay in the sow group influenced the eating rank significantly. The eating rank increased from nulliparous to multiparous sows (Table 2). Figure 6 shows that nulliparous sows had the lowest rank during the whole gestation period with a linear increase depending on duration of stay in the sow group. These sows reached the intermediate rank $(E R=0)$ around day 77 after moving into the dynamic sow group. Primiparous and biparous sows increased their eating rank faster than nulliparous sows ( $E R=0$ before day 40 ). Older sows had the highest eating rank. Their $E R$ increased until day 60 in the sow group and starting from day 25 the eating rank was greater than zero. 


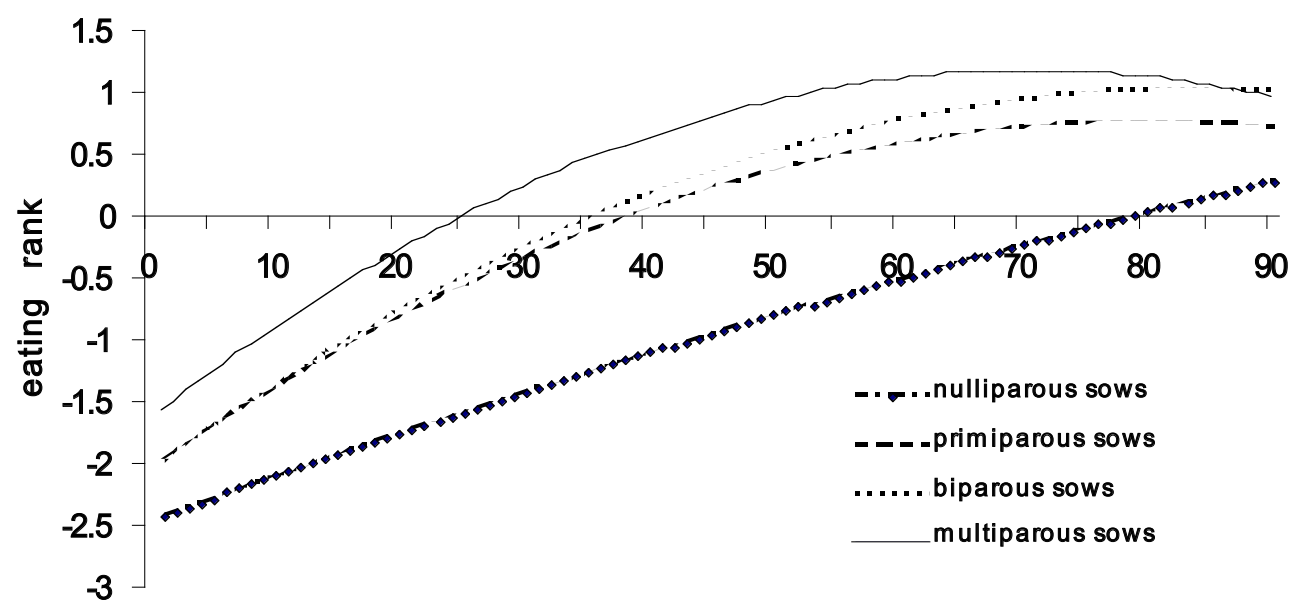

duration of stay in the sow group

Figure 6

Eating rank depending on duration of stay in the sow group and parity class

The repeatability of FD, FMD, pauseF and FV were low to moderate indicating a low to moderate variation between sows. The eating rank had a higher value representing a useful parameter for disease detection since only little variation was observed between adjacent days (Table 2). The autocorrelation ranged from 0.42 to 0.64 , indicating that the autocorrelation should be considered to obtain valid statistical interference and correct variance components for feeding and drinking behavioural traits.

\section{Analysis of water intake behaviour}

Significant influences of parity class, test day and duration of stay in the sow group were estimated for the trait DD. The traits DMD, pauseW and DV were influenced significantly by test day and the linear effect of duration in the sow group while parity showed no influence. The drinking duration per day (DD) of primiparous, biparous and multiparous sows was higher than that of nulliparous sows $(P<0.05)$ (Table 3). The DMD, pauseW and DV varied between parities but without a clear tendency. Drinking duration (DD) took only a small part of the whole drinking bout duration (DMD) compared to feed intake.

Table 3

Influence of parity class on the traits of water intake behaviour (Least Square Means (LSM) and their standard error (SE)), repeatability (w) and autocorrelation ( $\rho$ )

\begin{tabular}{lcccrcc}
\hline \multicolumn{7}{c}{ Parity class } \\
& Nulliparous & Primiparous & \multicolumn{1}{c}{ Biparous } & Multiparous & w & $\rho$ \\
\hline DD, min & $4.6^{\mathrm{a}}(0.3)$ & $5.2^{\mathrm{b}}(0.3)$ & $5.5^{\mathrm{b}}(0.3)$ & $5.9^{\mathrm{b}}(0.4)$ & 0.55 & 0.48 \\
DMD, min & $68.6(5.3)$ & $73.5(4.2)$ & $72.3(4.5)$ & $69.9(5.7)$ & 0.46 & 0.35 \\
pauseW, min & $64.1(5.1)$ & $68.3(4.0)$ & $66.8(4.3)$ & $64.0(5.5)$ & 0.45 & 0.34 \\
DV & $11.2(0.6)$ & $11.6(0.5)$ & $11.5(0.6)$ & $11.8(0.7)$ & 0.52 & 0.43 \\
\hline
\end{tabular}

Values with different letters are significantly different $(P<0.05)$ within row 
Depending on the duration in the sow group the DMD showed a decreasing course for all parity classes (Figure 7). Primiparous sows had the highest DMD after moving into the dynamic sow group. The pattern decreased rapidly and reached the lowest value at the end of the observation period.

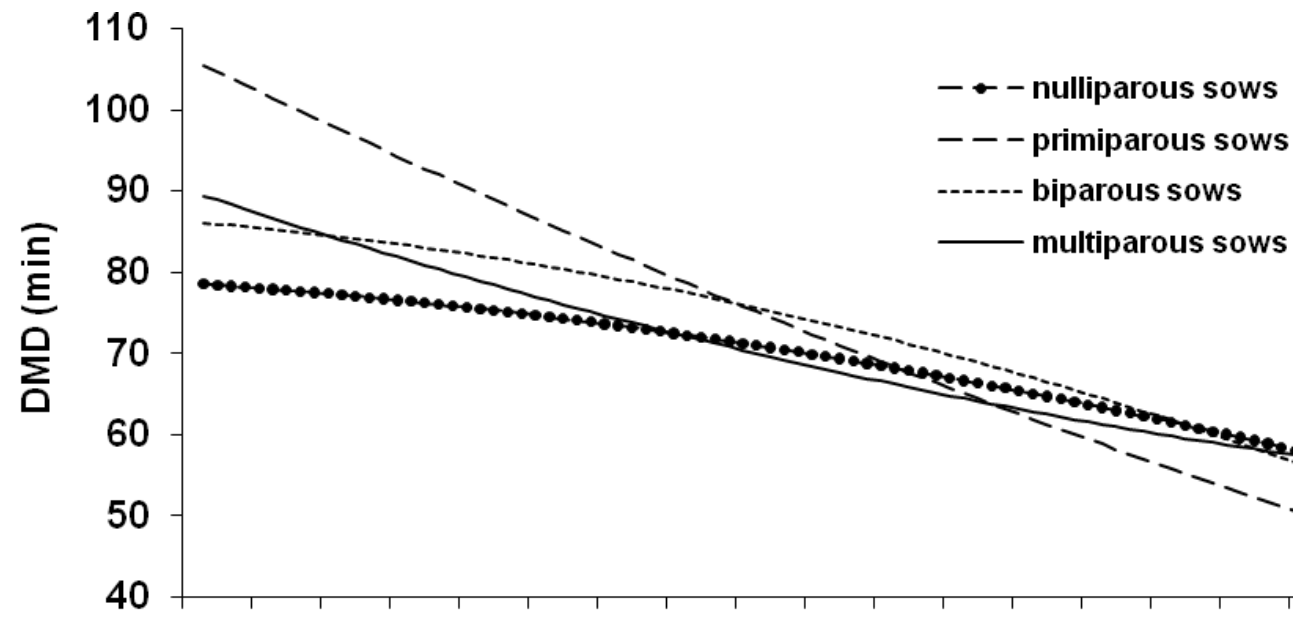

\section{duration of stay in the sow group}

\section{Figure 7}

Drinking meal duration (DMD) depending on duration of stay in the sow group and parity class

The traits of water intake behaviour had a higher repeatability than the traits of feed intake behaviour indicating a higher variation between sows. Autocorrelations were low to moderate $(0.34$ to 0.48$)$, but they showed the importance of its consideration.

\section{Discussion}

The basis for differentiating feed and water intake into bouts is the recording of single visits of sows at the feeding or drinking station. Several studies used only the feed intake of animals to calculate the meal criterion (Slater \& Lester 1982, Sibly et al. 1990, Morgan et al. 2000). The present study differentiated between water and feed intake because water was available ad libitum in contrast to feed, which was provided restrictively. The satiety concept could be applied only for water intake and in consequence a differentiated analysis between drinking and feeding behaviour would be preferable. The log survivorship function is a useful method to split feed and water intake events into bouts (Slater \& Lester 1982). It is based on the satiety concept which predicts the probability of an animal to initiate a meal. The function contains the hypothesis that the probability of an animal initiating a meal is very low immediately after ending a meal due to satiety. 


\section{Feed and water intake of the sow group during the day}

Immediately after feeding had started at 06:00 a.m., sows consumed a high amount their feed demand, which was in line with Ingram \& Dauncey (1985). Simultaneously, the feed intake per meal had the highest value, which showed that a few sows ate while the others waited. The rapid decrease of the amount of feed intake per meal in the subsequent two hours and the still high amount of feed intake indicated that more sows of the ate simultaneously. Assuming that sows of higher order eat first, now sows with lower eating rank are at the station and might displace each other to receive their feed (Kranendonk et al. 2007). A few sows started their feed intake not before afternoon (results not shown), probably to avoid interactions at the feeding stations.

Water intake of the sow group increased in the early morning and reached its maximum around one hour after feeding start. This indicated that sows consumed feed before water. The water intake per meal and total amount of water intake was constant between 07:00 a.m. and 09:00 a.m. indicating that an equal number of sows consumed water.

\section{Feed and water intake behaviour}

All the parameters of feed intake behaviour were higher for nulliparous and primiparous (younger sows) sows in contrast to older sows. These results indicate that younger sows might be under stress during feed intake if they are housed together with older sows. Due to the fact that the present study used an open feeding station, younger sows could be displaced by heavier sows. The heavier sows dominated and took feed from the demand of smaller sows (Kranendonk et al. 2007). If a young sow had been displaced, it had to wait until the displacing sow had moved away from the feeder indicated by a higher pauseF of nulliparous and primiparous sows compared to older. Closed feeding stations could help to avoid displacing problems. Different pens for young and older sows might be another possibility but requires an appropriate large herd size. Ad libitum feeding could reduce competition for feed intake in open feeding stations but is not practical for gestation sows as their conditions would not be optimal for farrowing (Brouns \& Edwards 1994). Therefore, restricted feeding could be combined with additional rough feed or sows could be occupied with some materials (toys) such as balls.

The eating rank supported the results of the feed intake behaviour. Older sows had a higher rank than younger sows. The eating rank increased during gestation. This was in line with the observation of Cornou et al. (2008). Remience et al. (2008) pointed out that newly introduced sows had to integrate themselves into the group and at the order at the feeding station. In consequence, sows which stayed longer in the dynamic group ate first while sows introduced later ate later (Bressers et al. 1993). Multiparous sows started with a higher eating rank and increased it faster than younger sows which is certainly due to their higher body weight (Arey 1999, O'Connell et al. 2003, Hoy et al. 2009).

Water intake behaviour showed different results than feed intake behaviour since water was available ad libitum. Nulliparous sows had a lower DD than older sows due to the lowest water intake during pregnancy (Kruse et al. 2010).

The low to moderate repeatability of feed intake indicated that the variance between sows was low due to the restricted feeding. As expected, water intake had a higher repeatability 
since water was offered ad libitum. Both water intake and eating rank traits might be possible indicators of early disease detection (Edwards et al. 1988, Cornou et al. 2008).

Feed and water intake visits could be split into meals using the log survivor ship function. Using these criteria for deriving feeding and drinking behaviour the results emphasised that nulliparous and primiparous sows might be under stress during feed intake at the open feeding station since older sows displaced them. In contrast to feeding behaviour, the water intake behaviour did not create competition at the water station since it was available ad libitum. Water intake and eating rank might be used for disease detection. Both traits showed a moderate and high repeatability and they could be used for further studies.

\section{References}

Arey DS (1999) Time course for the formation and disruption of social organisation in group-housed sows. Appl Anim Behav Sci 62, 199-207

Bigelow JA, Houpt TR (1988) Feeding and drinking patterns in young pigs. Physiol Behav 43, 99-109

Beyga K, Rekiel A (2010) The effect of the body condition of late pregnant sows on fat reserves at farrowing and weaning and on litter performance. Arch Tierz 53, 50-64

Bressers HPM, Te Brake JHA, Engel B, Noordhuizen JPTM (1993) Feeding order of sows at an individual electronic feed station in a dynamic group-housing system. Appl Anim Behav Sci 36, 123-134

Brouns F, Edwards SA (1994) Social rank and feeding behavior of group-housed sows fed competitively or ad libitum. Appl Anim Behav Sci 39, 225-235

Cornou C, Vinther J, Kristensen AR (2008) Automatic detection of oestrus and health disorders using data from electronic sow feeders. Livest Sci 118, 262-271

De Haer LCM, Merks JWM (1992) Patterns of daily food intake in growing pigs. Anim Prod 54, 95-104

Edwards SA, Armsby AW, Large JW (1988) Effects of Feed Station Design on the Behavior of Group-Housed Sows Using an Electronic Individual Feeding System. Livest Prod Sci 19, 511-522

GfE (2006) Empfehlungen zur Energie- und Nährstoffversorgung von Schweinen 2006. Gesellschaft für Ernährungsphysiologie (GfE) DLG-Verlag, Frankfurt am Main, Deutschland [in German]

Hoy S, Bauer J, Borberg C, Chonsch L, Weirich C (2009) Investigations on dynamics of social rank of sows during several parities. Appl Anim Behav Sci 121, 103-107

Ingram DL, Dauncey MJ (1985) Circadian rhythms in the pig. Comp Biochem Physiol A Comp Physiol 82, 1-5

Kramer E, Stamer E, Spilke J, Krieter J (2008) Analysis of water intake, dry matter intake and daily milk yield using different error covariance structures. Animal 2, 1585-1594

Kranendonk G, van der Mheen $\mathrm{H}$, Fillerup M, Hopster H (2007) Social rank of pregnant sows affects their body weight gain and behavior and performance of the offspring. J Anim Sci 85, 420-429

Kruse S, Stamer E, Traulsen I, Krieter J (2010) Relationship between feed, water intake, and body weight in gestating sows. Livest Sci 137, 37-41

Littell RC, Henry PR, Ammerman CB (1998) Statistical analysis of repeated measures data using SAS procedures. J Anim Sci 76, 1216-1231

Littell RC, Milliken GA, Stroup WW, Wolfinger RD, Schabenberger O (2006) SAS for mixed models. User's manual. SAS Inc., Cary, NC, USA, 174-203

Morgan CA, Emmans GC, Tolkamp BJ, Kyriazakis I (2000) Analysis of the feeding behavior of pigs using different models. Physiol Behav 68, 395-403

Musial F, Kowalski A, Enck P, Kalveram KT (1999) A computer-controlled, long-term recording system for studying eating, drinking, and defecation behavior in miniature pigs. Physiol Behav 68, 73-80 
O'Connell NE, Beattie VE, Moss BW (2003) Influence of social status on the welfare of sows in static and dynamic groups. Anim Welf 12, 239-249

Remience V, Wavreille J, Canart B, Meunier-Salaun MC, Prunier A, Bartiaux-Thill N, Nicks B, Vandenheede M (2008) Effects of space allowance on the welfare of dry sows kept in dynamic groups and fed with an electronic sow feeder. Appl Anim Behav Sci 112, 284-296

SAS (2005) SAS/STAT User's Guide. Version 9.0. SAS Inc., Cary, NC, USA

Sibly RM, Nott HMR, Fletcher DJ (1990) Splitting behavior into bouts. Anim Behav 39, 63-69

Slater PJB, Lester NP (1982) Minimizing Errors in Splitting Behavior into Bouts. Behav 79, 153-161

Stamer E, Junge W, Kalm E (1997) Temporal pattern of feeding behaviour of dairy cows kept in groups. Arch Tierz 40, 195-214 [in German]

Received 3 January 2011, accepted 28 March 2011.

Corresponding author:

Imke Traulsen

email: itraulsen@tierzucht.uni-kiel.de

Institute of Animal Breeding and Husbandry, Christian-Albrechts-Universität zu Kiel, Olshausenstraße 40, 24098 Kiel, Germany 